\title{
Calcium fixation on fortified rice made with various rice varieties
}

\author{
${ }^{1}$ Wariyah, Ch., ${ }^{2}$ Anwar, C., ${ }^{3}$ Astuti, M. and ${ }^{3}$ Supriyadi \\ ${ }^{I}$ Department of Agricultural Product Technology, Faculty of Agroindustry, Universitas Mercu Buana \\ Yogyakarta, Indonesia, Jl. Wates Km 10, Yogyakarta 55244, Indonesia \\ ${ }^{2}$ Department of Chemistry, Faculty of Mathematic and Natural Science, Universitas Gadjah Mada, Sekip \\ Utara, Yogyakarta 55281, Indonesia \\ ${ }^{3}$ Department of Food Science, Faculty of Agricultural Technology, Universitas Gadjah Mada, Jl. Sosio \\ Yustisia, Bulaksumur, Yogyakarta 55281, Indonesia
}

\begin{abstract}
Article history:
Received: 12 June 2020

Received in revised form: 25 August 2020

Accepted: 14 October 2020

Available Online: 10 January 2021
\end{abstract}

Keywords:

Fortification,

Rice,

Amylose-content,

Calcium-retention

DOI:

https://doi.org/10.26656/fr.2017.5(1).348

\section{Introduction}

Calcium $\left(\mathrm{Ca}^{2+}\right)$ is an essential macromineral in the body that functioned as bone structural component, blood acid-base balance regulator (McCarthy and Kumar, 2004), nerve impulse transmission, muscle contraction, blood coagulation, hormone secretion and intercellular adhesion (Walker and Rolls, 1992). Therefore, calcium deficiency can cause bone abnormalities such as osteoporosis, rickets $(\mathrm{Pu}$ et al., 2016), and tetani (Desai et al., 2013). Currently, calcium intake in humans, especially in Asia, is still less than 400 $\mathrm{mg} /$ day (Harrison, 2017), whereas the Recommended Daily Intake of calcium is about $1000 \mathrm{mg}$ (FAO/WHO, 2001). The low calcium intake of Asian due to lack of calcium-rich food consumption such as milk, cheese and eggs. Therefore, fortification of calcium in food that consumed many people or staple food such as rice was important. The calcium content of rice was between 4.25 and $6.32 \mathrm{mg} / 100 \mathrm{~g}$ polished-rice (Reddy et al., 2017).
Therefore, fortification was carried out on rice to improve its nutritional quality.

Fortification is a part of nutrification, i.e. the addition of one or more nutrients to food commonly consumed to obtain, control or increase the dietary intake of groups, communities or populations (Bauernfeind and Lachance, 1991). Calcium fortification of the rice was done by soaking in a Ca-lactate $0.5 \%-3 \%$ solution then steaming for 10 mins. The results showed that the increase of calcium in rice was about $50-100 \mathrm{mg} / 100 \mathrm{~g}$ of rice (Lee et al., 1995; Hettiarachchy et al., 1996). $\mathrm{Ca}^{2+}$ loss after washing was only $5 \%$ and $\mathrm{Ca}^{2+}$ retention after dialysis was $60 \%$. It was assumed that $\mathrm{Ca}^{2+}$ was trapped in a gel formed when steaming and there was an interaction of $\mathrm{Ca}^{2+}$ with starch molecules. The high retention of $\mathrm{Ca}^{2+}$ in rice was assumed because $\mathrm{Ca}^{2+}$ acts as a crosslinker and was held inside the gelatinized starch matrix by ionic-dipole bonds. Wariyah et al. (2014), found that the texture of calcium-fortified rice 
was harder than that of normal rice. This showed that during the process of making calcium-fortified rice, the rice underwent gelatinization and became hard after drying, so that $\mathrm{Ca}^{2+}$ trapping was stronger.

According to Oscik (1982), the adsorption of liquids into solids could take place physically or chemically. Hettiarachchy et al. (1996) stated that calcium fortification by immersion at high temperatures allowed physical adsorption and capillary condensation because hydrated $\mathrm{Ca}^{2+}$ was able to form weak hydrogen bonds and ionic-dipole bonds with starch molecules. In addition, the high temperatures used in rice soaking could also cause calcium fixation by $\mathrm{Ca}^{2+}$ trapping in a three-dimensional network from gelatinized starch.

The main component of rice is starch, a compound consisting of amylose and branched amylopectin molecules in molar ratios of $15 \%$ to $25 \%$ and $85 \%$ to $75 \%$, respectively (Tako et al., 2014). Amylose and amylopectin of the starch molecules have many hydroxyl groups (-OH) (Champagne, 2004), so the potential for interactions with $\mathrm{Ca}^{2+}$ is high. According to the amylose content, rice is divided into three types, namely low amylose rice (12-20\%), medium amylose (20-25\%) and high amylose (25-33\%) (Juliano, 1993). Wariyah et al. (2010) stated that the calcium absorption rate into rice grain was influenced by the amylose content. The higher the rice amylose content, the lower the absorption rate of calcium and the higher the activation energy. In addition, the amylose straight-chain facilitates crosslinking with other molecules (Tester, 2004). In rice with a high amylose content, the gelatinization temperature is lower than that of low amylose rice (Lii et al., 1996). The gelatinization temperatures of high amylose rice (IR-42), medium amylose (Ciherang) and low amylose (Memberamo) are $63.0^{\circ} \mathrm{C} ; 72.5^{\circ} \mathrm{C}$ and $63.4^{\circ} \mathrm{C}$, respectively (Wariyah et al., 2014). Rice gelatinization during soaking at high temperatures had a more open structure, making it easier to bind $\mathrm{Ca}^{2+}$. However, when heating reaches a certain gelatinization level, amylose will leach together with the formation of gel (Lii et al., 1996). In high amylose rice, after gelatinization, retrogradation would immediately occur (Jung et al., 2016), so that absorbed substance trapping is stronger. The aim of this study was to evaluate the calciumbinding mechanism in rice that underlies calcium stability in Ca-fortified rice.

\section{Materials and methods}

\subsection{Materials}

Low-, medium- and high- amylose rice grains represented by Memberamo, Ciherang and IR-42 varieties were obtained from The Rice Research
Institute, Sukamandi, Subang, West Java, Indonesia. The grains were hulled and polished twice with a Da ichi blower rice polisher. The whole rice was then used as research material. Calcium salts used $\mathrm{Ca}$ lactate (Calcium lactate pentahydrate, Sigma Aldrich Chemie, $\mathrm{Gm}$ ) and Ca-gluconate (Brataco Chemika), dialysis membrane MWCO 7000 from SnakeSkinTM Pleated Dialysis Tubing (Pierce Chemical Company) and deionized water were used as solvents.

\subsection{Instrumentation}

Da ichi blower rice polisher (type N50 from Da ichi Engineering Co., Ltd.) was used to hull and polish the rice grains, and shaker waterbath (Kotterman D-3162) was used for infusing calcium solution into rice, temperature controlled by thermocouple (Hanna Instruments HI 92704C K-Thermocouple). Fluidized Bed Drier (Armfield series 1253-2) for rice drying and calcium content on the fortified-rice and normal rice (control) were analyzed by using an Atomic Absorption Spectrometer (AAS, GBC 932 AA). The infrared spectra of the calcium-fortified rice and the normal rice were analyzed using an Infrared (FT-IR) mid-infrared Fourier Transform-Infrared spectrometer (FT-IR, Shimadzu, Prestige-21).

\subsection{Procedure}

Calcium-fortified rice made from low-, medium- and high- amylose rice was processed by the infusion method Wariyah et al. (2008), at $80^{\circ} \mathrm{C}$ using a shaker waterbath and dried with a fluidized bed drier and temperature controlled by thermocouple. Calcium-fortified rice and normal rice (control) were analyzed for their calcium content using an atomic absorption spectrometer and moisture content measured using the static gravimetric method (AOAC, 1990). The infrared spectra of the calcium-fortified rice and the normal rice were analyzed using an Infrared (FT-IR) mid-infrared. Samples for testing with the FT-IR were prepared as pellets made with $0.6 \%$ sample (flour form) mixed with $\mathrm{KBr}$, refer to Hardjono (2001). The pattern of calcium fixation in the rice was determined by mid-infrared at frequencies between 4000-400 $\mathrm{cm}^{-1}$, based on the changes of $\mathrm{Ca}^{2+}$ binding spectra which were estimated in the $-\mathrm{OH}$ group of the starch molecules and $\mathrm{C}-\mathrm{O}$ which vibrated. The group could be detected at wavenumbers around 3300 $\mathrm{cm}^{-1}$ and 1200-900 $\mathrm{cm}^{-1}$ (Lizuka and Aishima, 1999). If the group interacted with $\mathrm{Ca}^{2+}$, it would cause changes in the absorption bands from the resulting FT-IR spectra. 


\section{Results and discussion}

\subsection{Calcium content of normal and Ca-fortified rice}

The $\mathrm{Ca}^{2+}$ content of normal rice and calciumfortified rice of low-, medium- and high amylose rice is shown in Table 1. The results of this study show the $\mathrm{Ca}^{2+}$ of normal rice to be between $4.36-5.02 \mathrm{mg} / 100 \mathrm{~g}$ dry matter, while the $\mathrm{Ca}^{2+}$ of fortified-rice was between 101.38 - $109.40 \mathrm{mg} / 100 \mathrm{~g}$ (with Ca-lactate fortificant) and between $102.77-119.55 \mathrm{mg} / 100 \mathrm{~g}$ dry matter (with Ca-gluconate fortificant). The $\mathrm{Ca}^{2+}$ normal rice content was about $4.25-6.32 \mathrm{mg} / 100 \mathrm{~g}$ polished rice (Reddy et al., 2017). According to Wariyah et al. (2010), calcium in rice was influenced by processing conditions, such as the ratio of rice to calcium solution and the varieties of rice, but the range of calcium content in rice was similar, i.e. between $101.38-119.5 \mathrm{mg} / 100 \mathrm{~g}$ of rice (dry matter).

Table $1 . \mathrm{Ca}^{2+}$ content on calcium fortified-rice $(\mathrm{mg} / 100 \mathrm{~g}$ dry matter)

\begin{tabular}{lccc}
\hline & $\begin{array}{c}\text { Low amylose } \\
\text { rice }\end{array}$ & $\begin{array}{c}\text { Medium } \\
\text { amylose rice }\end{array}$ & $\begin{array}{c}\text { High amylose } \\
\text { rice }\end{array}$ \\
\cline { 2 - 4 } (Memberamo) & (Ciherang) & (IR-42) \\
\hline Normal rice & $4.92 \pm 0.04$ & $4.36 \pm 0.03$ & $5.02 \pm 0.02$ \\
Ca-fortified rice added with : & & \\
Ca-lactate & $108.21 \pm 3.74$ & $101.38 \pm 1.37$ & $109.40 \pm 5.92$ \\
Ca-gluconate & $102.77 \pm 5.75$ & $109.87 \pm 1.50$ & $119.55 \pm 1.95$ \\
\hline
\end{tabular}

\subsection{Spectra FT-IR and $\mathrm{Ca}^{2+}$ fixation}

Calcium fixation on rice was determined in both normal rice and calcium-fortified rice types with low amylose (Memberamo), medium amylose (Ciherang) and high amylose (IR-42) varieties which were fortified with $\mathrm{Ca}$-lactate or Ca-gluconate. The rice was soaked in a calcium solution at $80^{\circ} \mathrm{C}$ which caused rice starch gelatinization (Wariyah et al., 2014). Hettiarachchy et al. (1996) and Bryant and Hamaker (1997) stated that starch gelatinization caused $\mathrm{Ca}^{2+}$ trapping in a threedimensional network of starch gel and interaction of $\mathrm{Ca}^{2+}$ with starch molecules. Figure $1-3$ shows the spectra of normal rice with low amylose (LA-R), medium amylose (MA-R) and high amylose (HA-R) and calcium-fortified rice with Ca-lactate (LA-R-CaL, MA-R-CaL, HA-R$\mathrm{CaL}$ ) or Ca-gluconate (LA-R-CaG, MA-R-CaG, HA-R$\mathrm{CaG})$. Recapitulation of the FT-IR band area of the spectral absorption of rice and calcium-fortified rice is shown in Table 2.

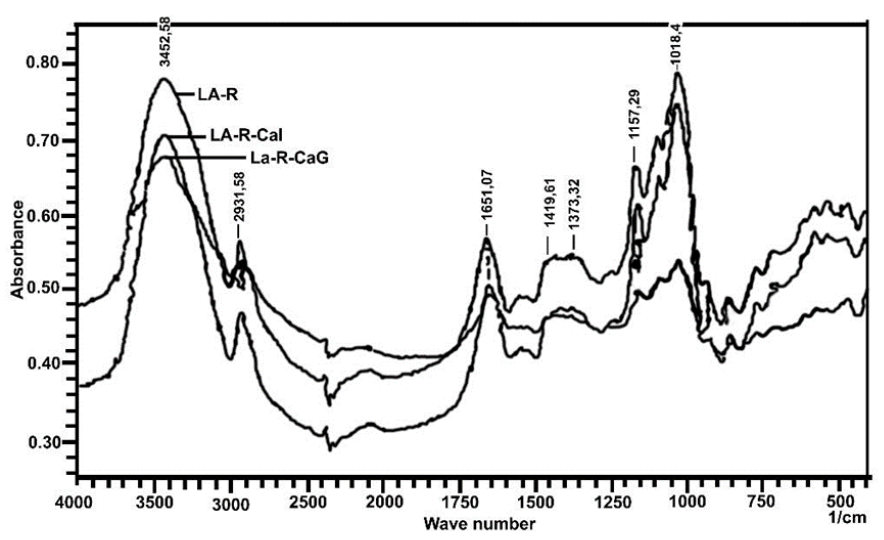

Figure 1. Calcium fortified-rice spectra of low amylose rice, LA-R: Normal Low Amylose Rice, LA-R-CaL: Low Amylose Rice with added Ca-Lactate, and LA-R-CaG: Low Amylose Rice with added Ca-Gluconate

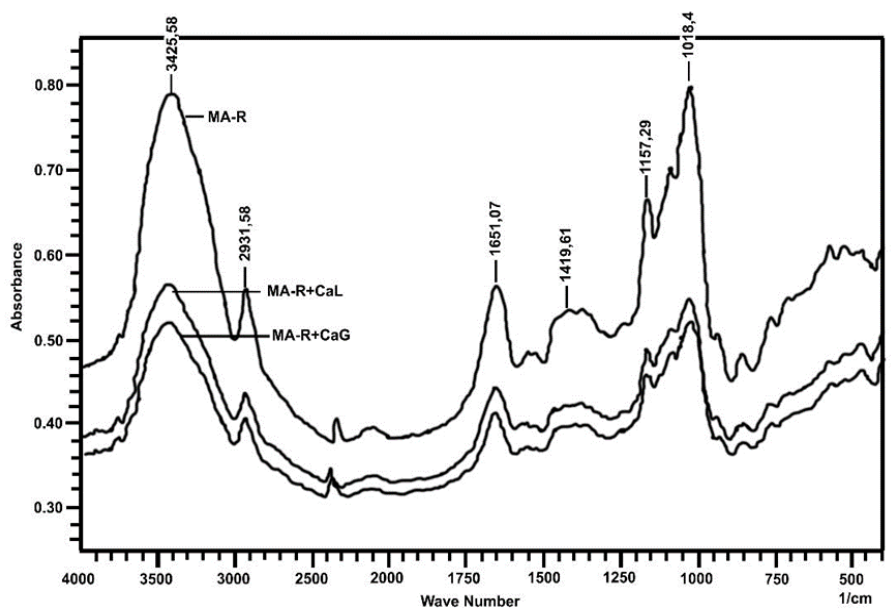

Figure 2. Calcium fortified-rice spectra of medium amylose rice, MAR: Normal Medium Amylose Rice, MA-R-CaL: Medium Amylose Rice with added Ca-Lactate, and MA-R$\mathrm{CaG}$ : Medium Amylose Rice with added Ca-Gluconate

Table 2. FT-IR spectra of normal rice and calcium fortified-rice

\begin{tabular}{lcccc}
\hline \multirow{2}{*}{\multicolumn{1}{c}{ Rice type }} & \multicolumn{4}{c}{ Wavenumber $\left(\mathrm{cm}^{-1}\right)$} \\
\cline { 2 - 5 } & 1018.41 & 1026.13 & 1157.29 & 3425.58 \\
\hline Low amylose (normal rice) & 79.814 & - & 54.823 & 481.900 \\
Low amylose (+Ca-lactate) & - & 73.744 & 45.454 & 414.376 \\
Low amylose (+Ca-gluconate) & - & 57.691 & 40.333 & 404.157 \\
Medium amylose (normal rice) & 79.616 & - & 49.995 & 482.402 \\
Medium amylose (+Ca-lactate) & - & 58.375 & - & 323.568 \\
Medium amylose (+Ca-gluconate) & 55.632 & - & 39.736 & 299.171 \\
High amylose (normal rice) & 64.931 & - & 41.624 & 385.472 \\
High amylose (+Ca-lactate) & - & 54.702 & - & 353.494 \\
High amylose (+Ca-gluconate) & - & 55.283 & 37.123 & 318.108 \\
\hline
\end{tabular}




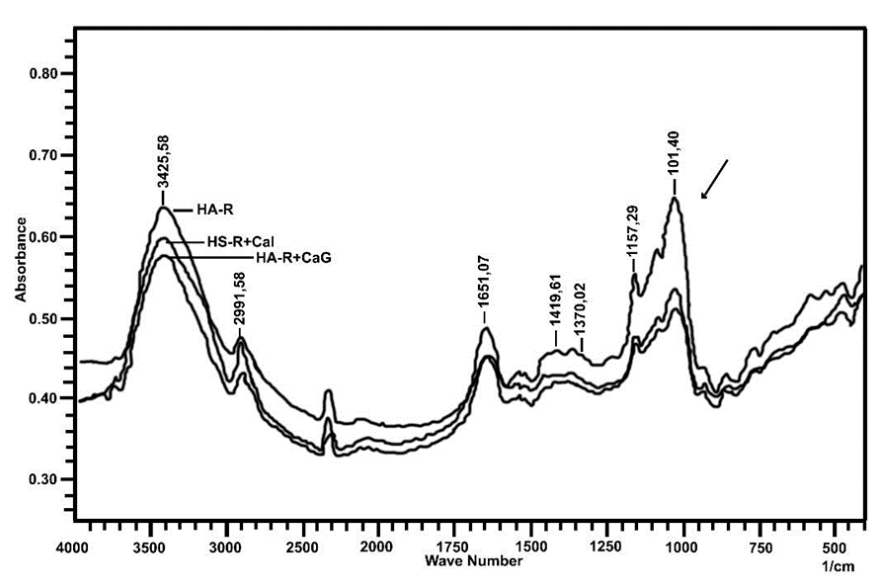

Figure 3. Calcium fortified-rice spectra of high amylose rice, HA-R: Normal High Amylose Rice, HA-R-CaL: High Amylose Rice with added Ca-Lactate, and HA-R-CaG: High Amylose Rice with added Ca-Gluconate

The main component of rice is starch, which is composed of amylose and amylopectin molecules. Amylose and amylopectin molecules constitute glucose polymers $\left(\mathrm{C}_{6} \mathrm{H}_{12} \mathrm{O}_{6}\right)$, therefore there are many -OH groups and $\mathrm{C}-\mathrm{O}$ bonds. According to Lizuka and Aishima (1999), FT-IR spectra from rice starch showed 4 spectral peaks at $3300,1610,1350$ and $1000 \mathrm{~cm}^{-1}$. The spectra at 3300 and $1610 \mathrm{~cm}^{-1}$ were from water molecules, while the peak of $1350 \mathrm{~cm}^{-1}$ was the O-C-H bending mode (curve); C-C-H and C-O-H had peaks at 1200 and $900 \mathrm{~cm}^{-1}$ and showed strong absorption of stretching mode (stretch) of $\mathrm{C}-\mathrm{C}$ and $\mathrm{C}-\mathrm{O}$ groups. According to Cooper (1980) and Hardjono (2001), spectra between $3400-2400 \mathrm{~cm}^{-1}$ showed the $-\mathrm{OH}$ group (hydroxyl), while the spectra between $1280-1000 \mathrm{~cm}^{-1}$ showed a C-O group.

This study, with FT-IR spectrometers on LA-R, MA$\mathrm{R}$ and HA-R rice and calcium-fortified rice (LA-R-CaL, MA-R-CaL, HA-R-CaL and LA-R-CaG, MA- R-CaG, HA-R-CaG), showed 4 specific spectral peaks at wave numbers of $3425.0 \mathrm{~cm}^{-1}$ and $1157.29 \mathrm{~cm}^{-1} ; 1026.13 \mathrm{~cm}^{-1}$; $1018.14 \mathrm{~cm}^{-1}$. Stretching vibration at wave number 3425 $\mathrm{cm}^{-1}$ showed the $-\mathrm{OH}$ group, and at the wavenumbers of $1157.29 \mathrm{~cm}^{-1} ; 1026.13 \mathrm{~cm}^{-1} ; 1018.14 \mathrm{~cm}^{-1}$ was a $\mathrm{C}=\mathrm{O}$ group. According to Anugrahati et al. (2017), rice flour spectra (normal rice) had functional groups similar to those of Menthik Susu and Ramos Sentra rice varieties. The group included $-\mathrm{OH}$ in spectra with wave numbers $3749.62 \mathrm{~cm}^{-1}, 3425.58 \mathrm{~cm}^{-1}$ and $3387 \mathrm{~cm}^{-1} ; \mathrm{C}=\mathrm{O}$ at $1157.29 \mathrm{~cm}^{-1}$ and $\mathrm{C}-\mathrm{OH}$ at bending vibrations at 856.39 $\mathrm{cm}^{-1}$ and $578.64 \mathrm{~cm}^{-1}$. These groups were mainly on glucose molecules that comprised amylose and amylopectin and these results were in accordance with this study. However, when seen at the peak area (Table 2) it appeared that the addition of Ca-lactate and $\mathrm{Ca}$ gluconate caused a decrease in the absorption band area or a decrease in absorbance of the group at wavenumbers
$1018.41 \mathrm{~cm}^{-1} ; 1026.13 \mathrm{~cm}^{-1} ; 1157.29 \mathrm{~cm}^{-1}$ and $3425 \mathrm{~cm}^{-}$ 1. According to Domagala (2012), the absorption band intensity in infrared spectra was expressed in absorbance (A) namely $\mathrm{A}=-\log 10$ (I/Io), (Io and $\mathrm{I}$ are light intensities before and after interacting with the sample). Strong interactions were indicated by high absorbance values. In rice without added calcium, absorbance and absorption band areas were high, meaning that there was a high interaction between specific functional groups at certain frequencies in the sample, while the reduction in absorbance value, or area of the band, indicating a decrease in the number of functional groups. The addition of calcium salts can cause a part of the -OH group to bind to $\mathrm{Ca}^{2+}$ and the $\mathrm{C}-\mathrm{O}$ bond in rice starch to vibrate so that the absorbance or area of the band area decreases.

According to Wariyah et al. (2007), water absorption in rice is influenced by temperature. The higher the temperature, the greater the water absorption and at $85^{\circ} \mathrm{C}$ the increase in water absorption was very high, together with the occurrence of starch gelatinization. In this research, the fortification was carried out by soaking rice in a calcium solution, so that $\mathrm{Ca}^{2+}$ was hydrated and water was diffused into the rice grains. $\mathrm{Ca}^{2+}$ ions were hydrated and bound to about 12 water molecules, namely $\mathrm{Ca}\left(\mathrm{H}_{2} \mathrm{O}\right)_{12}$ (Bush et al., 2008). Possible interactions between $\mathrm{Ca}^{2+}$ and starch were physical adsorption between $\mathrm{Ca}^{2+}$ which had undergone hydration with the $\mathrm{O}$ atoms of starch molecules through hydrogen binding. In addition, when the rice was soaked in a calcium solution at high temperatures, gelatinization or formation of 3dimensional networks occurred, so that water and $\mathrm{Ca}^{2+}$ became trapped in the starch gel. The strong calcium interaction in calcium-fortified rice had been demonstrated in the results of previous studies which showed that high $\mathrm{Ca}^{2+}$ retention from washing was about $86.23-94.39 \%$ which indicated the presence of $\mathrm{Ca}^{2+}$ trapped or bound to the components of rice. $\mathrm{Ca}^{2+}$ retention during dialysis was between $38.42-44.13 \%$. This showed the presence of $\mathrm{Ca}^{2+}$ which was bound to the starch component and was well trapped in the rice component. This means that there was a binding relationship of $\mathrm{Ca}^{2+}$ to rice from the results of testing FTIR spectra of calcium-fortified rice and rice.

According to Kariper and Kaya (2014), metal ions can act as receptors of electron pairs, or as Lewis acids, which can form co-ordination compounds, whereas glucose molecules composed of amylose and amylopectin have many - $\mathrm{OH}$ groups and $\mathrm{CO}$ bonds which can act as Lewis acids that could also act as donor electron pairs, or Lewis pairs, and as ligands. The interaction between $\mathrm{Ca}^{2+}$ and rice starch molecules may also involve chemical interactions with the formation of 
a coordination complex. Based on the band absorption changes in the -OH group and -C-O bonds (Table 2), the addition formed hydrogen bonds, and, it was estimated, formed $\mathrm{Ca}^{2+}$ complexes with starch through ionic-dipole bonds, especially in helical amylose molecules and cross -linked between amylose molecules. The size of the $\mathrm{Ca}$ atom is around $0.2 \mathrm{~nm}$, which allows binding in the helical amylose structure with a diameter of $1.4 \mathrm{~nm}$. According to Oscik (1980), physical adsorption occurs through weak bonds, so it is reversible and can break up by decreasing the solute concentration or increasing vapor pressure. In chemical adsorption, an adsorption energy of around $80-650 \mathrm{~kJ} / \mathrm{mol}$ or $19-155 \mathrm{kcal} / \mathrm{mol}$ is needed. Hydrogen bond energy is $0.5-9.6 \mathrm{kcal} / \mathrm{mol}$ (Fennema, 1996). In this study, there was no known energy of $\mathrm{Ca}^{2+}$ adsorption on rice. What was known was the water-binding energy in the monolayer, which was only about $87.87-190.93 \mathrm{kcal} / \mathrm{mol}$ or $0.09-0.19 \mathrm{kcal} /$ mol, so that the $\mathrm{Ca}^{2+}$ was weak (Wariyah and Supriyadi, 2010).

The addition of Ca-gluconate resulted in a band area and absorbance value smaller than Ca-lactate. This showed that the interaction of infrared light with the -OH group and the vibration of the $\mathrm{C}-\mathrm{O}$ bond was lower. The structure of Ca-gluconate is more complex and there are more - $\mathrm{OH}$ groups than $\mathrm{Ca}$-lactate. With a high molecular weight, the amount of $\mathrm{Ca}^{2+}$ of Ca-gluconate in the same amount with another calcium salt is more, so the possibility of interacting with the starch molecules is greater. According to Ruan and Chen (1998), hydrophilic substances such as proteins, carbohydrates (e.g. glucose) have side chains that could form hydrogen bonds such as dipole-electric forms - $\mathrm{OH}, \mathrm{COOH}, \mathrm{NH}_{3}+$ and COO-. Therefore, the more groups in Ca-gluconate that are able to interact with starch molecules, the lower the absorbance value after the addition of calcium.

\section{Conclusion}

From this study it can be concluded that calcium fixation in rice can be through the formation of hydrogen bonds between starch and Ca-hydrated ionic-dipole bonds between $\mathrm{Ca}^{2+}$ and -OH of starch molecules and trapping in gelatinized starch matrix, shown by decreases in the absorbance and the absorption band area at wave numbers of $3425 \mathrm{~cm}^{-1}$ (-OH group) and $1300-1000 \mathrm{~cm}^{-1}$ (CO group).

\section{Conflict of interest}

The authors herewith declare no conflict of interest.

\section{Acknowledgments}

We would like to thank the Directorate General of
Higher Education, Ministry of Education of the Republic of Indonesia, for financial assistance via the research project of the Competitive Research Grant Program.

\section{References}

Anugrahati, N.A., Pranoto, Y., Marsono, Y. and Marseno, D.W. (2017). Physicochemical properties of rice (Oryza sativa L.) flour and starch of two Indonesian rice varieties differing in amylose content. International Food Research Journal, 24(1), 108-113.

AOAC. (1990). Officials Methods of Analysis of AOAC International. $15^{\text {th }}$ ed. Arlington, Virginia: Association of Official Analytical Chemists, Inc.

Bauernfeind, J.C. and P. Lachance. (1991). Nutrient Additions to Food: Nutritional, Technological and Regulatory Aspect in Food and Nutrition. , p. 49. Connecticut, Trumbull, USA: Humana Press.

Bryant, C.M. and Hamaker, B.R. (1997). Effect of lime on gelatinization of corn flour and starch. Cereal Chemistry, 74(2), 171-1757. https://doi.org/10.1094/ CCHEM.1997.74.2.171

Bush, M.F., Saykally, R.J. and. William, E.R. (2008). Infrared action spectra of $\mathrm{Ca}^{2+}\left(\mathrm{H}_{2} \mathrm{O}\right)_{11-69}$ exhibit spectral signatures for condensed-phase structures with increasing cluster size. Journal of American Chemical Society, 130, 15482 - 15489. https:// doi.org/10.1021/ja804621r

Champagne, E.T. (2004). Rice: chemistry and technology. $3^{\text {rd }}$ ed. St Paul, USA: American Association of Cereal Chemists.

Cooper, J.W. (1980). Spectroscopic Techniques for Organic Chemist. New York: John Wiley and Sons.

Desai, M., Kolla, P.K. and Reddy, P.L.V.P. (2013). Calcium unresponsive hypocalcemic tetany: gitelman syndrome with hypocalcemia. Case Report in Medicine, 2013, $197374 . \quad \mathrm{https} / /$ doi.org/10.1155/2013/197374

Domagala, W.U. (2012). The Use of the Spectrometric Technique FTIR-ATR to Examine the Polymers Surface, p. 86. In Farrukh, M.A. (Ed.) Advanced Aspects of Spectroscopy. InTech Open E-book.

FAO/WHO. (2001). Human Vitamin and Mineral Requirement. FAO-WHO Food and Nutrition Division. FAO Rome. Retrieved on July 10, 2020 from FAO website: http://www.fao.org/3/ay2809e.pdf

Fennema, O.R. (1996). Principles of Food Science. New York, USA: Marcell Dekker Inc.

Hardjono, S. (2001). Spectroscopy. Yogyakarta, Indonesia: Liberty. 
Harrison, P. (2017). Dietary Calcium Intake Poor in much of the World. Retrieved on July 5, 2020 from Medscape website: https://www.medscape.com/ viewarticle/888206.

Hettiarachchy, N., Gnanasambandam R. and Lee, M.H. (1996). Calcium fortification of rice: distribution and retention. Journal of Food Science, 61(1), 195-1976. https://doi.org/10.1111/j.1365-2621.1996.tb14758.x

Juliano, B. (1993). Rice in Human Nutrition. Food And Agriculture Organization of the United Nations. Retrieved on July 5, 2020 from FAO website: http:// www.fao.org/3/t0567e/T0567E00.htm.

Jung, K.G.H., Lee, S.H. and Kim, J.C. (2016). Retrogradation of heat-gelatinized rice grain in sealed packaging: investigation of moisture relocation. Food Science and Technology, 37(1), 97102. https://doi.org/10.1590/1678-457x.07816

Kariper, S.E. and Kaya, C. (2014). Effect of some electron donor and electron acceptor groups on stability of complexes according to the Principle of HSAB. Journal of New Results in Science, 4, 82-89.

Lee, M.H., Hettiarachchy, N.S., McNew, R.W. and Gnanasambandam, R. (1995). Physicochemical properties of calcium-fortified rice. Cereal Chemistry, 72(4), 352-355.

Lii, C.Y., Tsai, M.L. and Tseng, K.H. (1996). Effect of amylose content on the rheological property of rice starch. Cereal Chemistry, 73(4), 415-420.

Lizuka, K. and Aishima, T. (1999). Starch gelation process observed by FT-IR/ATR spectrometry with multivariate data analysis. Journal Food Science, 64 (4), 653-658. https://doi.org/10.1111/j.13652621.1999.tb15104.x

McCarthy, J.T. and Kumar, R. (2004). Divalent Cation Metabolism: Calcium. Retrieved on March 29, 2009 Kidney Atlas website: from www.kidneyatlas.org.

Oscik, J. (1982). Adsorption. New York: E. Horwood, Halsted Press Chichester.

$\mathrm{Pu}, \mathrm{F}$., Chen, N. and Xue, S. (2016). Calcium intake, calcium homeostasis and health. Food Science and Human Wellness, 5(1), 8-16. https://doi.org/10.1016/ j.fshw.2016.01.001

Reddy, C.K., Kimi, L. Haripriya, S. and Kang, N. (2017). Effects of polishing on proximate composition, physico-chemical characteristics, mineral composition and antioxidant properties of pigmented rice. Rice Science, 24(5), 241-252. https://doi.org/10.1016/j.rsci.2017.05.002

Ruan, R.R. and P. Chen, P. (1998). Water in Food. New York, USA: CRC Press.

Tako, M., Tamaki, Y., Teruya, T. and Takeda, Y. (2014). The Principles of starch gelatinization and retrogradation. Food and Nutrition Sciences, 5(3), 280-291. https://doi.org/10.4236/fns.2014.53035

Tester, R.F., Karkalas, J. and Qi, X. (2004). Starch structure and digestibility Enzyme-Substrate relationship. World's Poultry Science Journal, 60(2), 186-195. https://doi.org/10.1079/WPS20040014

Walker, A.F. and Rolls, B.A. (1992). Nutrition and the Consumer: Issues in Nutrition and Toxicology. London and New York: Elsevier Applied Science.

Wariyah, C., Anwar, C., Astuti, M. and Supriyadi. (2007). Kinetics of water absorption in rice. Agritech, 27(3), 112-117.

Wariyah, C., Anwar, C., Astuti, M. and Supriyadi. (2008). Physical properties and acceptability of calcium fortified-rice. Agritech, 28(1), 34-42.

Wariyah, C. and Supriyadi. (2010). Moisture Sorption Isotherm of Calcium-Fortified Rice. Agritech, 30(4), 199-203.

Wariyah, C., Astuti, M., Supriyadi and Anwar, C. (2010). Calcium absorption kinetic on Indonesian rice. Indonesian Journal of Chemistry, 8(2), 252257. https://doi.org/10.22146/ijc. 21630

Wariyah, C., Anwar, C., Astuti, M. and Supriyadi. (2014). Pasting properties of calcium-fortified rice. International Food Research Journal, 21(3), 989993. 